\title{
Evaluation of Comprehensive Urban Disaster Prevention and Reduction Based on Coupling Synergy Theory
}

\author{
Zhuo Song ${ }^{1}$, Wei Wang ${ }^{1,2}$, Xiaodong Guo ${ }^{1,2}$ \\ ${ }^{1}$ Institute of Earthquake Resistance and Disaster Reduction, Beijing University of Technology, Beijing 100124, China \\ ${ }^{2}$ College of Architecture and Engineering, Beijing University of Technology, Beijing 100124, China \\ ieeww@bjut.edu.cn
}

城市综合防灾复合系统耦合协调度评价模型

\author{
宋卓 1 , 王威 1,2 , 郭小东 1,2 \\ 1 北京工业大学抗震减灾研究所, 北京 100124 , 中国 \\ 2 北京工业大学建筑与城市规划学院, 北京 100124 , 中国 \\ ieeww@bjut.edu.cn
}

\begin{abstract}
In order to make a more objective evaluation of the level of coordinated development of the integrated urban disaster prevention complex system, the complex mechanism of coupling and co-evolution is analyzed from five aspects, such as monitoring early warning and prediction, engineering defense, emergency disposal and rescue. By constructing evaluation index system of complex system of urban comprehensive disaster prevention, coupling and coordination degree as input variables, building the coupling coordination degree model, and Jiangxi province as an example for empirical analysis. The results show that the coupling degree of various cities in Jiangxi province is high, which is basically located in $(0.8,1)$ interval, and there is strong interaction between each subsystem, which belongs to the high level coupling stage. However, the overall coupling of the five subsystems in each city is relatively low, which is basically in the $(0.2,0.4)$ range, and the benign coupling degree is low, which belongs to the type of mild or moderate disorder. The coordination degree of the subsystem coupling is basically the same as the overall coupling, and the individual cities are slightly different. The results of the coupling coordination in every city show the consistency in spatial distribution and the circular distribution on the radar map.
\end{abstract}

Keywords-disaster prevention and mitigation, coupling and synergy, subsystem, the coupling degree, coordination

摘要一为更客观评价城市综合防灾复合系统的协调发 展水平, 运用耦合理论和协调理论, 从监测预警预报能力、 工程防御能力、应急处置与救援救助能力等五种方面解析 子系统之间存在的复杂耦合协调演化机制。通过构建城市 综合防灾复合系统评价指标体系, 以耦合度与协调度为输 入变量, 构建耦合协调度模型, 并以江西省各城市为例进 行实证计算分析。结果表明: 江西省各城市耦合程度高, 基本位于（0.8, 1) 区间, 各子系统之间存在强的相互作 用, 属于高水平耦合阶段; 而各城市五大子系统整体耦合 的协调度较低, 基本在 $(0.2,0.4)$ 区间内, 良性耦合程度 较低, 属于轻度或中度失调发展类型; 子系统耦合的协调 度情况与整体耦合基本相同, 个别城市略有差异; 各城市
耦合协调结果在空间分布上表现出一致性, 在雷达图上呈 圆形分布。

关键词一防灾减灾; 耦合协同; 子系统; 耦合度; 协调度

$$
\text { I. 引言 }
$$

面对全球自然灾害频发, 我国城市灾害风险进一 步加大的现状，城市综合防灾复合系统日益受到人们 的重视。城市综合防灾复合系统作为城市灾害防御的 整体保障，由多个子系统构成，并在多个子系统共同 作用下发挥灾害防御能力, 因此研究如何统筹协调子 系统的发展情况, 怎样保证最大程度地提高城市综合 防灾减灾能力, 对城市安全具有重要作用和重大意义。 所以有必要进一步研究城市综合防灾复合系统协调发 展机理, 确定城市综合防灾复合系统的评价模型与方 法[1-2]。

国内外的学者在城市综合防灾减灾系统评价方面 进行了大量的研究工作。在国内, 周彪等[3]结合改 进的层次分析法与灰色关联投影评价法对城市防灾减 灾综合能力进行定量分析。金晨等[4]建立甘肃省县 级行政单位地震预防和减灾能力评价指标体系，运用 专家评分法确定权重, 层次分析法确定抗震防灾减灾 能力。王威等[5]从城市灾害危险性、易损性和承灾 能力三个方面建立评价指标体系, 并采用的实用概率 方法对城市综合防灾与减灾能力进行评价。王威 [6] 在云模型理论的基础上, 对城市防灾减灾能力评价进 行研究。张明媛等[7]建立指标体系, 采用可变模糊 聚类方法, 对城镇综合承灾能力进行评价。胡俊锋等 [8]在建立评价指标体系的基础上，建立区域评价模 型, 采用层次分析和人工神经网络两种方法对区域综 合减灾能力进行评价。在国外，1999年美国斯坦福大 学的 Davidsond 等[9]以 EDRI(earthquake disaster risk index)为指标, 来判断各个城市灾害强度与灾害特性。 日本学者 Kunihiroi 等[10]分析阪神地震的震害情况后 认为, 该城市的抗震能力或地震易损性受多种影响因 素决定。基于对影响因素的分析，他们提出了一种城 
市抗震能力的综合性、定量化的评价方法。美国保险 机构构建了包含多个消防指标的城市消防分级体系, 来帮助评价城市火灾风险[11]。

在耦合协调理论研究方面, 刘志亭[12]应用协调 度概念, 通过确定指标权重和指标标准化, 得到三个 系统的分系统协调度, 并以此建立能源-经济-环境三 个系统之间总协调度的数学函数评价模型。该模型对 整体和局部两个层次的协调度都进行的分析, 只缺乏 对系统耦合度的研究。吴跃明等[13]以协调学为基础, 通过构建指标体系、计算序参量功效函数、协调度函 数建立协调度模型。黄友均等 [14]通过构建指标体系, 使用变异系数法建立环境与经济发展协调度模型, 并 以此来评价其发展协调度的变化。祝爱民等[15]在模 糊数学理论的基础上, 利用隶属度函数和模糊综合评 价法对科技进步与经济发展的情况进行实证分析与研 究。刘艳清[16]基于灰色系统理论, 建立区域协调度 模型, 并以辽宁省为例进行研究。江红莉等[17]基于 一般系统论中系统演化的思想来建立区域经济与生态 环境的系统动态平衡模型, 对江苏省经济与生态环境 进行实证研究。王滨等[18]根据耦合协同理论与熵值 赋权理论, 建立泥石流耦合协调模型, 并进行了耦合 协调度和危险性的评价。

近些年, 国内外学者对城市综合防灾复合系统评 价进行了有益的探索, 然而很少有学者将耦合协同理 论应用到城市综合防灾复合系统评价。有鉴于此, 本 文以耦合协同理论为基础, 从整体耦合到子系统耦合, 分别构建指标体系, 建立模型, 对城市综合防灾复合 系统进行评价。

\section{II. 耦合协同理论}

\section{A. 耦合度与协调度}

耦合可应用于多个领域，具体是指两个或两个以 上的系统或运动形式通过各种相互作用而彼此影响的 现象, 是在各子系统间的良性互动下相互依赖、相互 协调和相互促进的动态关联关系 [18]。

系统内的序参量相互促进, 系统的功能被强化, 序参量相互阻碍, 系统的功能被减弱, 因此, 系统内 的序参量决定系统的发展趋势。耦合度正是用来反映 序参量之间相互作用的度量, 并不区分促进, 还是阻 碍。因此用耦合度度量监测预警预报能力、工程防御 能力、应急处置与救援救助能力、社会经济基础支撑 能力、灾害管理能力相互作用的影响程度。

协调是以实现系统总体演进为目标, 两种或两种 以上相互关联的系统或系统要素组成一个统一整体、 协调一致时的一种良性循环态势及其控制过程 [18]。 当各个系统或各个系统中的影响因子互相促进, 良性 循环, 系统趋向于有序的状态。当各个系统或各个系 统中的影响因子互相干扰, 恶性循环, 系统趋向于无 序的状态。协调就是系统达到有序时的状态, 此时的 系统内部各个要素有机地联系在一起。在这样的一个 状态下，系统内的元素相互促进，协调一致，促使整 个系统更加合理。协调度是度量系统之间或系统内部 要素之间在发展过程中彼此和谐一致的程度，体现了 相互作用中良性耦合的程度[19]。

\section{B. 城市综合防灾复合系统协调发展机理}

城市综合防灾复合系统是区域在防灾备灾、应急 处置、救援救助和灾后恢复重建等灾害管理全过程的 复合系统。城市综合防灾减灾既要有减灾工程措施的 作用, 也要有非工程措施的作用, 必须综合考虑灾前、 灾中和灾后全过程，统筹考虑灾害管理各个环节的多 种因素，使得多种防灾减灾能力如监测预警预报、工 程防御、应急处置与救援救助等能力相互协调相互促 进，努力实现城市综合防灾减灾能力最大化。而各子 系统对自身能力最大化的追求，使城市综合防灾复合 系统表现出一定的无序性，导致一定程度的相互阻碍。 因此，利用耦合协同理论，建立城市综合防灾复合系 统耦合协调模型，开展城市综合防灾复合系统耦合协 调评价, 满足城市综合防灾减灾要求, 可以为城市综 合防灾复合系统耦合协调评价与提高提供理论支持。

\section{III. 城市综合防灾复合系统耦合协同度评价模型}

\section{A. 指标体系构建}

综合考虑城市综合防灾复合系统的影响因素、确 定城市综合防灾复合系统耦合协调评价指标体系，综 合国内外专家学者的研究结论, 以系统性、有效性、 完整性和可比性原则以及数据获取的简单性、易操作 性，将城市综合防灾复合系统划分为监测预警预报能 力子系统、工程防御能力子系统、应急处置与救援救 助能力子系统、社会经济基础支撑能力子系统、灾害 管理能力子系统等五个子系统。

评价指标往往具有不同的量纲, 数据差异较大, 为了达到指标间的可比性和可测性，需要对各项评价 指标的原始数据进行归一化处理, 以消除指标量纲的 影响, 评价指标标准化公式为:

$$
u_{i j}= \begin{cases}\frac{x_{i j}-\min \left(x_{i j}\right)}{\max \left(x_{i j}\right)-\min \left(x_{i j}\right)}, & u_{i j} \text { 具有正功效 } \\ \frac{\max \left(x_{i j}\right)-x_{i j}}{\max \left(x_{i j}\right)-\min \left(x_{i j}\right)}, & u_{i j} \text { 具有负功效 }\end{cases}
$$

式中, $u_{i j}$ 为指标标准化后的值; $x_{i j}$ 为指标实际值; $i, j$ 为指标个数; $\max \left(x_{i j}\right)$ 为指标中的最大值; $\min \left(x_{i j}\right)$ 为指标中的最小值。

系统内部序参量（即各子系统）有序程度的 总贡献利用下面的公式计算:

$$
U_{i}=\sum_{j=1}^{n} \lambda_{i j} \cdot u_{i j}
$$

式中, $n$ 为影响因子个数; $U_{i}$ 为第 $i$ 个子系统对总系统 有序度的贡献值, $\lambda_{i j}$ 为第 $i$ 个序参量中第 $j$ 个影响因子 的权重。

\section{B. 耦合协调模型}

基于物理学的容量耦合概念及容量耦合系数模型, 推广得到多个系统相互作用的耦合度模型, 即: 


$$
C=m\left(\frac{U_{1} \cdot U_{2} \cdot U_{3} \cdots U_{m}}{\left(U_{1}+U_{2}+U_{3}+\cdots+U_{m}\right)^{m}}\right)^{\frac{1}{m}}
$$

式中: $C$ 为系统耦合度, $C \in(0,1), m$ 为子系统个数。 $U_{m}$ 分别表示第 $m$ 个子系统对有序度的贡献值。
根据相关的文献说明 ${ }^{[19]}$ 及城市综合防灾减灾规律, 将耦合度划分为四个阶段： $0.0<\mathrm{C} \leq 0.3$ 低水平耦合阶 段； $0.3<\mathrm{C} \leq 0.5$ 拮抗阶段； $0.5<\mathrm{C} \leq 0.8$ 磨合阶段； $0.8<\mathrm{C} \leq 1.0$ 高水平耦合阶段。

表 1 子系统两两耦合协调类型判断标准

Table1 Judgment standard of two subsystems coupling coordination type judgment standard

\begin{tabular}{|c|c|c|c|c|}
\hline 大类 & $\begin{array}{c}\text { 耦合协调度 } \\
\text { D }\end{array}$ & 小类 & $U_{i}, U_{j}$ 对比 & 基本类型 \\
\hline \multirow{9}{*}{ 协调发展类 } & \multirow{3}{*}{$0.90-1.00$} & \multirow{3}{*}{ 优质协调发展类 } & $U_{i}>U_{j}$ & 优质协调发展类 $U_{j}$ 子系统滞后型 \\
\hline & & & $U_{i}=U_{j}$ & 优质协调发展类 $U_{i}$ 与 $U_{j}$ 同步型 \\
\hline & & & $U_{i}<U_{j}$ & 优质协调发展类 $U_{i}$ 子系统滞后型 \\
\hline & \multirow{3}{*}{$0.70-0.90$} & \multirow{3}{*}{ 良好协调发展类 } & $U_{i}>U_{j}$ & 良好协调发展类 $U_{j}$ 子系统滞后型 \\
\hline & & & $U_{i}=U_{j}$ & 良好协调发展类 $U_{i}$ 与 $U_{j}$ 同步型 \\
\hline & & & $U_{i}<U_{j}$ & 良好协调发展类 $U_{i}$ 子系统滞后型 \\
\hline & \multirow{3}{*}{$0.60-0.70$} & \multirow{3}{*}{ 中级协调发展类 } & $U_{i}>U_{j}$ & 中级协调发展类 $U_{j}$ 子系统滞后型 \\
\hline & & & $U_{i}=U_{j}$ & 中级协调发展类 $U_{i}$ 与 $U_{j}$ 同步型 \\
\hline & & & $U_{i}<U_{j}$ & 中级协调发展类 $U_{i}$ 子系统滞后型 \\
\hline \multirow{9}{*}{ 过渡发展类 } & \multirow{3}{*}{$0.50-0.60$} & \multirow{3}{*}{ 初级协调发展类 } & $U_{i}>U_{j}$ & 初级协调发展类 $U_{j}$ 子系统滞后型 \\
\hline & & & $U_{i}=U_{j}$ & 初级协调发展类 $U_{i}$ 与 $U_{j}$ 磨合型 \\
\hline & & & $U_{i}<U_{j}$ & 初级协调发展类 $U_{i}$ 子系统滞后型 \\
\hline & \multirow{3}{*}{$0.40-0.50$} & \multirow{3}{*}{ 勉强协调发展类 } & $U_{i}>U_{j}$ & 勉强协调发展类 $U_{j}$ 子系统滞后型 \\
\hline & & & $U_{i}=U_{j}$ & 勉强协调发展类 $U_{i}$ 与 $U_{j}$ 磨合型 \\
\hline & & & $U_{i}<U_{j}$ & 勉强协调发展类 $U_{i}$ 子系统滞后型 \\
\hline & \multirow{3}{*}{$0.30-0.40$} & \multirow{3}{*}{ 轻度失调发展类 } & $U_{i}>U_{j}$ & 轻度失调发展类 $U_{j}$ 子系统滞后型 \\
\hline & & & $U_{i}=U_{j}$ & 轻度失调发展类 $U_{i}$ 与 $U_{j}$ 磨合型 \\
\hline & & & $U_{i}<U_{j}$ & 轻度失调发展类 $U_{i}$ 子系统滞后型 \\
\hline \multirow{6}{*}{ 失调发展类 } & \multirow{3}{*}{$0.10-0.30$} & \multirow{3}{*}{ 中度失调发展类 } & $U_{i}>U_{j}$ & 中度失调发展类 $U_{j}$ 子系统滞后型 \\
\hline & & & $U_{i}=U_{j}$ & 中度失调发展类 $U_{i}$ 与 $U_{j}$ 拮抗型 \\
\hline & & & $U_{i}<U_{j}$ & 中度失调发展类 $U_{i}$ 子系统滞后型 \\
\hline & \multirow{3}{*}{$0.00-0.10$} & \multirow{3}{*}{ 严重失调发展类 } & $U_{i}>U_{j}$ & 严重失调发展类 $U_{j}$ 子系统滞后型 \\
\hline & & & $U_{i}=U_{j}$ & 严重失调发展类 $U_{i}$ 与 $U_{j}$ 共损型 \\
\hline & & & $U_{i}<U_{j}$ & 严重失调发展类 $U_{i}$ 子系统滞后型 \\
\hline
\end{tabular}

表 2 系统整体耦合协调类型判断标准与能力水平划分

Table 2 The overall system to coordinate the type of coordination and the level of capacity

\begin{tabular}{|c|c|c|c|}
\hline $\bar{D}$ & 耦合协调类型 & 能力水平 & 城市综合防灾复合系统描述 \\
\hline $0.000 \sim 0.300$ & 低度耦合协调 & 低水平 & $\begin{array}{l}\text { 子系统间相互促进、协同演进程度差, 各影响因子值较 } \\
\text { 小, 协调配合导致城市综合防灾减灾能力水平较低, 抵御 } \\
\text { 灾害的能力较弱 }\end{array}$ \\
\hline $0.300 \sim 0.500$ & 中度耦合协调 & 中等水平 & $\begin{array}{l}\text { 子系统间存在着一定程度的相互促进、协同演进作用, 部 } \\
\text { 分影响因子值较大, 协调配合尚可, 能抵御中等强度的灾 } \\
\text { 害 }\end{array}$ \\
\hline $0.500 \sim 0.800$ & 高度耦合协调 & 高水平 & $\begin{array}{l}\text { 子系统间相互促进作用很大, 系统协同演进性强, 影响因 } \\
\text { 子值大, 耦合协调程度好, 能抵御大强度的灾害 }\end{array}$ \\
\hline $0.800 \sim 1.000$ & 极度耦合协调 & 极高水平 & $\begin{array}{l}\text { 子系统间相互促进作用强烈, 系统协同演进性极强, 影响 } \\
\text { 因子值很大, 耦合协调程度极佳, 能抵御极大强度的灾害 }\end{array}$ \\
\hline
\end{tabular}


1) 两子系统耦合协调度

两子系统耦合度计算如下

$$
C=2 \times \sqrt{\frac{U_{i} \cdot U_{j}}{\left(U_{i}+U_{j}\right)^{2}}}
$$

两子系统耦合协调度计算如下:

$$
\begin{gathered}
D=\sqrt{C \cdot T} \\
T=\alpha \cdot U_{i}+\beta \cdot U_{j}
\end{gathered}
$$

式中, $\alpha, \beta$ 分别为对应子系统的权重值, $U_{i}, U_{j}$ 分别表 示第 $i, j$ 个子系统对有序度的贡献值。表 1 对子系统两两 耦合协调类型进行了划分。

\section{2) 系统整体耦合协调度}

本耦合系统中包括五个子系统, 即 $m=5$, 则系统 耦合度及其耦合协调度计算公式如下:

$$
\begin{gathered}
C=5\left\{\frac{U_{1} \cdot U_{2} \cdot U_{3} \cdot U_{4} \cdot U_{5}}{\left(U_{1}+U_{2}+U_{3}+U_{4}+U_{5}\right)^{5}}\right\}^{\frac{1}{5}} \\
D=\sqrt{C \cdot T}
\end{gathered}
$$

式中, $D$ 为系统耦合协调度, $T$ 为综合协调指数，反映 城市综合防灾减灾系统的整体协同效应。表 2 对系统 整体耦合协调类型进行了划分。

$$
T=a \cdot U_{1}+b \cdot U_{2}+c \cdot U_{3}+d \cdot U_{4}+e \cdot U_{5}
$$

式中, $a, b, c, d, e$ 分别为各子系统的权重值。

\section{IV. 实例分析}

\section{A. 数据来源及权重确定}

本文以江西省为例具体进行分析计算, 数据主要来 自：一是江西省及其下辖 11 个市的统计年鉴; 二是通过 相关部门获取专业数据; 三是通过向灾害专家或基层灾 害工作人员发放调查问卷获得数据, 数据总体可靠和可 信[8]。

考虑到评价的客观性和准确性在遵循主观判断和客 观分析相结合的原则上, 根据专家意见, 通过构造判断

\begin{tabular}{|c|c|c|c|c|c|}
\hline 地市 & $\begin{array}{c}\text { 监测预警 } \\
\text { 预报能力 } \\
\left(U_{1}\right) \\
(\mathbf{0 . 1 6 5 )}\end{array}$ & $\begin{array}{c}\text { 应急处 } \\
\text { 置与救 } \\
\text { 援能力 } \\
\left(U_{2}\right) \\
(0.297)\end{array}$ & $\begin{array}{c}\text { 工程防 } \\
\text { 御能力 } \\
\left(U_{3}\right) \\
(\mathbf{0 . 1 9 7})\end{array}$ & $\begin{array}{c}\text { 社会经 } \\
\text { 济支撑 } \\
\text { 能力 } \\
\left(U_{4}\right) \\
(0.169)\end{array}$ & $\begin{array}{c}\text { 灾害管 } \\
\text { 理能力 } \\
\left(U_{5}\right) \\
(\mathbf{0 . 1 7 4})\end{array}$ \\
\hline 抚州 & 0.044 & 0.123 & 0.075 & 0.019 & 0.053 \\
\hline 赣州 & 0.063 & 0.147 & 0.076 & 0.042 & 0.063 \\
\hline 吉安 & 0.060 & 0.109 & 0.128 & 0.029 & 0.084 \\
\hline 景德镇 & 0.067 & 0.162 & 0.098 & 0.099 & 0.078 \\
\hline 九江 & 0.071 & 0.179 & 0.142 & 0.114 & 0.091 \\
\hline 南昌 & 0.095 & 0.191 & 0.118 & 0.103 & 0.135 \\
\hline 萍乡 & 0.077 & 0.088 & 0.070 & 0.054 & 0.037 \\
\hline 上饶 & 0.069 & 0.105 & 0.085 & 0.066 & 0.041 \\
\hline 新余 & 0.064 & 0.140 & 0.090 & 0.093 & 0.057 \\
\hline 宜春 & 0.068 & 0.212 & 0.059 & 0.046 & 0.074 \\
\hline 鹰潭 & 0.066 & 0.145 & 0.083 & 0.084 & 0.045 \\
\hline
\end{tabular}
矩阵、层次单排序及其一致性检验, 确定权重 (指标括 号内数据为该指标权重)，具体结果如表 3 所示 [8]。

表 3 江西省各地(市)单项减灾能力评价结果

Table 3 Evalucation results of single disaster reduction ability of each city(prefecture) in Jiangxi Province

B. 子系统两两耦合的耦合协调度计算

利用公式 (4) 计算两子系统间耦合度 $C$, 利用公式

\begin{tabular}{|c|c|c|c|c|c|c|c|c|c|c|c|c|c|c|c|}
\hline \multirow{2}{*}{ 地市 } & \multicolumn{3}{|c|}{$U_{1}$ 与 $U_{2}$ 耦合协调 } & \multicolumn{3}{|c|}{$U_{1}$ 与 $U_{3}$ 耦合协调 } & \multicolumn{3}{|c|}{$U_{1}$ 与 $U_{4}$ 耦合协调 } & \multicolumn{3}{|c|}{$U_{1}$ 与 $U_{5}$ 耦合协调 } & \multicolumn{3}{|c|}{$U_{2}$ 与 $U_{3}$ 耦合协调 } \\
\hline & $C$ & $\boldsymbol{T}$ & $D$ & $C$ & $T$ & $D$ & $C$ & $T$ & $D$ & $C$ & $T$ & $D$ & $C$ & $T$ & D \\
\hline 抚州 & 0.882 & 0.095 & 0.289 & 0.966 & 0.061 & 0.243 & 0.919 & 0.032 & 0.170 & 0.996 & 0.049 & 0.220 & 0.971 & 0.089 & 0.294 \\
\hline 赣州 & 0.916 & 0.117 & 0.327 & 0.995 & 0.070 & 0.264 & 0.981 & 0.052 & 0.226 & 1.000 & 0.063 & 0.251 & 0.948 & 0.103 & 0.313 \\
\hline 吉安 & 0.956 & 0.091 & 0.295 & 0.931 & 0.097 & 0.300 & 0.940 & 0.044 & 0.204 & 0.985 & 0.072 & 0.267 & 0.997 & 0.091 & 0.301 \\
\hline 景德镇 & 0.908 & 0.128 & 0.341 & 0.982 & 0.084 & 0.286 & 0.981 & 0.083 & 0.285 & 0.997 & 0.072 & 0.268 & 0.969 & 0.117 & 0.337 \\
\hline 九江 & 0.903 & 0.141 & 0.356 & 0.944 & 0.110 & 0.322 & 0.973 & 0.093 & 0.301 & 0.993 & 0.081 & 0.284 & 0.993 & 0.136 & 0.367 \\
\hline 南昌 & 0.942 & 0.156 & 0.384 & 0.994 & 0.107 & 0.327 & 0.999 & 0.099 & 0.314 & 0.984 & 0.116 & 0.337 & 0.972 & 0.138 & 0.366 \\
\hline 萍乡 & 0.998 & 0.084 & 0.290 & 0.999 & 0.073 & 0.271 & 0.984 & 0.065 & 0.254 & 0.934 & 0.056 & 0.230 & 0.994 & 0.067 & 0.258 \\
\hline 上饶 & 0.978 & 0.092 & 0.301 & 0.995 & 0.078 & 0.278 & 1.000 & 0.067 & 0.260 & 0.968 & 0.055 & 0.230 & 0.994 & 0.080 & 0.283 \\
\hline 新余 & 0.929 & 0.113 & 0.323 & 0.986 & 0.078 & 0.278 & 0.983 & 0.079 & 0.278 & 0.998 & 0.060 & 0.246 & 0.977 & 0.102 & 0.315 \\
\hline 宜春 & 0.858 & 0.161 & 0.371 & 0.997 & 0.063 & 0.250 & 0.981 & 0.057 & 0.236 & 0.999 & 0.071 & 0.267 & 0.824 & 0.139 & 0.338 \\
\hline 鹰潭 & 0.928 & 0.117 & 0.329 & 0.994 & 0.075 & 0.273 & 0.993 & 0.075 & 0.274 & 0.982 & 0.056 & 0.234 & 0.962 & 0.104 & 0.315 \\
\hline \multirow{2}{*}{ 地市 } & \multicolumn{3}{|c|}{$U_{2}$ 与 $U_{4}$ 耦合协调 } & \multicolumn{3}{|c|}{$U_{2}$ 与 $U_{5}$ 耦合协调 } & \multicolumn{3}{|c|}{$U_{3}$ 与 $U_{4}$ 耦合协调 } & \multicolumn{3}{|c|}{$U_{3}$ 与 $U_{5}$ 耦合协调 } & \multicolumn{3}{|c|}{$U_{4}$ 与 $U_{5}$ 耦合协调 } \\
\hline & $C$ & $T$ & $D$ & $C$ & $T$ & $D$ & $C$ & $T$ & $D$ & $C$ & $T$ & $D$ & $C$ & $T$ & $D$ \\
\hline 抚州 & 0.683 & 0.085 & 0.241 & 0.918 & 0.097 & 0.299 & 0.805 & 0.049 & 0.199 & 0.985 & 0.065 & 0.253 & 0.884 & 0.036 & 0.179 \\
\hline 赣州 & 0.834 & 0.109 & 0.301 & 0.918 & 0.116 & 0.326 & 0.959 & 0.060 & 0.241 & 0.996 & 0.070 & 0.264 & 0.980 & 0.053 & 0.228 \\
\hline 吉安 & 0.817 & 0.080 & 0.255 & 0.992 & 0.100 & 0.314 & 0.779 & 0.082 & 0.253 & 0.979 & 0.107 & 0.324 & 0.875 & 0.057 & 0.223 \\
\hline 景德镇 & 0.970 & 0.139 & 0.367 & 0.935 & 0.131 & 0.350 & 1.000 & 0.098 & 0.313 & 0.993 & 0.088 & 0.296 & 0.993 & 0.088 & 0.295 \\
\hline 九江 & 0.975 & 0.156 & 0.389 & 0.945 & 0.147 & 0.372 & 0.994 & 0.129 & 0.358 & 0.976 & 0.118 & 0.339 & 0.994 & 0.102 & 0.319 \\
\hline 南昌 & 0.954 & 0.159 & 0.389 & 0.985 & 0.170 & 0.410 & 0.998 & 0.111 & 0.333 & 0.998 & 0.126 & 0.355 & 0.991 & 0.119 & 0.344 \\
\hline 萍乡 & 0.970 & 0.075 & 0.271 & 0.912 & 0.069 & 0.251 & 0.991 & 0.062 & 0.249 & 0.950 & 0.054 & 0.227 & 0.982 & 0.045 & 0.210 \\
\hline 上饶 & 0.973 & 0.091 & 0.297 & 0.899 & 0.082 & 0.271 & 0.992 & 0.076 & 0.275 & 0.938 & 0.065 & 0.246 & 0.974 & 0.053 & 0.228 \\
\hline 新余 & 0.980 & 0.123 & 0.347 & 0.907 & 0.109 & 0.315 & 1.000 & 0.092 & 0.303 & 0.974 & 0.075 & 0.270 & 0.971 & 0.075 & 0.270 \\
\hline 宜春 & 0.766 & 0.152 & 0.341 & 0.877 & 0.161 & 0.376 & 0.993 & 0.053 & 0.229 & 0.993 & 0.066 & 0.256 & 0.972 & 0.060 & 0.242 \\
\hline 鹰潭 & 0.965 & 0.123 & 0.344 & 0.852 & 0.108 & 0.304 & 1.000 & 0.083 & 0.289 & 0.957 & 0.065 & 0.250 & 0.954 & 0.065 & 0.248 \\
\hline
\end{tabular}
（9）、（10）分别计算综合协调指数 $T$ 和耦合协调度 $D$, 计算结果如表 4所示。并将结果通过雷达图显示出来, 由 于篇幅有限所以选取其中 3 个图，如图 1 所示。

表 4 各子系统两两耦合的耦合协调度

Table4 Coupling degree of coupling of each subsystem 


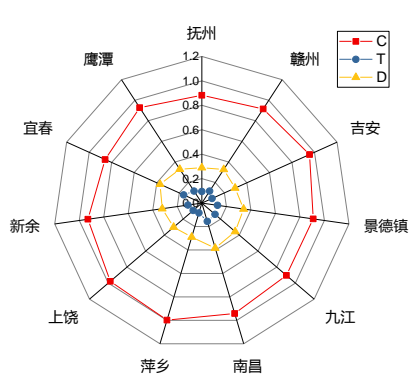

(a) $U_{1}$ 与 $U_{2}$ 耦合协调关系图

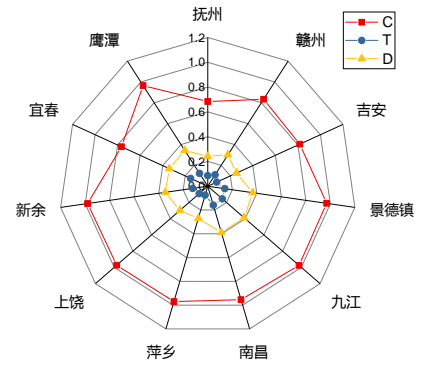

(b) $U_{2}$ 与 $U_{4}$ 耦合协调关系图

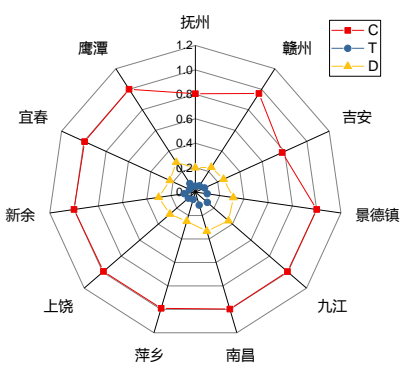

(c) $U_{3}$ 与 $U_{4}$ 耦合协调关系图

图 1 子系统耦合协调雷达图

Figure1 Subsystem coupled coordinated radar figure

\section{C. 城市综合防灾复合系统耦合协调度计算}

利用公式 (8) 计算城市综合防灾复合系统的耦合度 $C$, 利用公式（9）、（10）计算城市综合防灾复合系统 的耦合协调度 $D$ 和综合协调指数 $T$, 计算结果详见表 5 。

表 5 城市综合防灾复合系统耦合协调度

Table 5 Coupling coordination degree of urban comprehensive disaster prevention and control system.

\begin{tabular}{cccc}
\hline 地市 & $\mathbf{C}$ & $\mathbf{T}$ & $\mathbf{D}$ \\
\hline 抚州 & 0.842 & 0.071 & 0.245 \\
赣州 & 0.915 & 0.087 & 0.282 \\
吉安 & 0.888 & 0.087 & 0.278 \\
景德镇 & 0.953 & 0.109 & 0.322 \\
九江 & 0.950 & 0.128 & 0.349 \\
南昌 & 0.969 & 0.136 & 0.363 \\
萍乡 & 0.956 & 0.068 & 0.255 \\
上饶 & 0.955 & 0.078 & 0.272 \\
新余 & 0.950 & 0.095 & 0.301 \\
宜春 & 0.850 & 0.106 & 0.301 \\
鹰潭 & 0.930 & 0.092 & 0.293 \\
\hline
\end{tabular}

D. 耦合协调度评价分析

\section{1) 两子系统耦合协调度分析}

$U_{1}$ 与 $U_{2}$ 耦合协调关系图代表大部分两两耦合协调图 的情况, 分析图 $(a)$, 这十一座城市 $U_{1}$ 与 $U_{2}$ 的耦合度比较 高, 基本位于 $(0.8,1)$ 区间。但同时由于这十一座城 市的综合协调指数 $T$ 与耦合度 $C$ 相比较低, 在 0.1 上下浮 动, 导致耦合协调度都并不高, 其中南昌最高, 也仍属 轻度失调发展类。并且监测预警预报能力 $U_{1}$ 的发展滞后 于应急处置与救援能力 $U_{2}$ 。这些城市监测预警预报能力 和应急处置与救援能力发展差距比较大, 两者协调程度 不足, 交互带动作用及协调发展情况并不十分理想。

$U_{2}$ 与 $U_{4}$ 耦合协调关系图与多数关系图相比特殊一些, 从图中可以看出, 抚州和宜春的数据有一点内凹, 与多 数雷达图不太一样。这十一座城市应急处置与救援能力 子系统 $U_{2}$ 与社会经济基础支撑能力子系统 $U_{4}$ 的耦合度比 较高, 最大值 0.980 , 最小 0.683 。对于耦合协调度 $D$ 而 言, 这十一座城市的耦合协调度都不高, 基本均属中轻 度失调发展类, 并且社会经济基础支撑能力滞后。这些
城市的应急处置与救援能力和社会经济基础支撑能力之 间存在一定差距, 导致这两者出现轻度失调问题。

$U_{3}$ 与 $U_{4}$ 耦合协调关系图和 $U_{2}$ 与 $U_{4}$ 耦合协调关系图有 点类似, 也是有两个城市的数据有一点内凹。从表中数 据可以看出, 这十一座城市工程防御能力子系统 $U_{3}$ 与社 会经济基础支撑能力子系统 $U_{4}$ 的耦合度同样比较高, 其 中景德镇、新余、鹰潭达到 1 。但同样也是综合协调指数 小, 在 0.1 上下浮动, 导致这十一座城市的耦合协调度都 并不高, 九江最大 0.358 , 仍属中轻度失调发展类。

综合以上对子系统进行两两耦合的分析可以发现城 市子系统两两耦合的耦合度基本位于 $0.8<\mathrm{C} \leq 1.0$ 内, 属 于高水平耦合阶段; 耦合协调度比较低, 多数属于轻度 失调发展类。这说明两两子系统之间有特别强的相互作 用, 但根据耦合协调度可以判断这种作用并不都是协调 促进的, 各个子系统两两之间协同性较差, 相互协调促 进程度较低, 存在一定程度的不协调因素。

\section{2) 系统耦合协调度分析}

通过表 5 数据结果可知江西省表中所列城市的耦合度 均较高, 都位于 $0.8<\mathrm{C} \leq 1.0$ 区间内, 属于高水平耦合阶 段。这比较充分的表明江西省十一个城市的监测预警预 报能力子系统、工程防御能力子系统、应急处置与救援 救助能力子系统、社会经济基础支撑能力子系统和灾害 管理能力子系统之间的耦合程度总体高, 且均属于高水 平耦合阶段。

对城市综合防灾复合系统进行耦合协调度分析, 这 十一座城市对于监测预警预报能力子系统、工程防御能 力子系统、应急处置与救援能力子系统、社会经济基础 支撑能力子系统和灾害管理能力子系统之间综合协调指 数 $T$ 远低于耦合度 $C, T$ 值在 0.1 上下浮动, 导致协调度 $D$ 比较差, 基本在 $0.2<\mathrm{D} \leq 0.4$ 区间内, 多属于轻度失调发 展类或中度失调发展类。

\section{V. 结论}

1、本文建立了城市综合防灾复合系统耦合协调度评 价模型, 明确了耦合协调度的划分标准, 分析了江西省 11 市系统及两子系统间的耦合协调度情况, 提出了一种 基于耦合协同理论的城市综合防灾复合系统耦合协调度 评价方法。

2、本文不仅分析了城市综合防灾复合系统耦合协调 度的总体情况, 也对任意两个子系统进行了耦合协调度 
分析, 可以知道子系统之间相互促进的良性发展程度, 互相制肘和彼此阻碍的程度，有利于城市综合防灾发展 策略的调整，为城市综合防灾决策提供了依据和参考。

3、本文以江西省 11 个城市的综合防灾进行评价分 析, 建议对能力发展滞后的部分进行加强和改进, 评价 结果比较客观的反映了城市综合防灾减灾的现状, 为城 市综合防灾复合系统协调发展提供一定的理论基础和方 法支撑。更加完善的数据资料, 有助于对城市综合防灾 复合系统耦合协调度评价模型作进一步探讨。

\section{致谢}

本项目受中国地震局重大政策理论与实践问题研究课 题(CEAZY2019JZ14) ; 中国地震局地震工程与工程振动 重点实验室重点专项(2019EEEVL0501); 国家重点研发 计划课题（2018YFD1100902-1）; 国家自然科学基金项 目(51678017)资助。

\section{参考文献}

[1] 郑远长, “防灾减灾的基础研究及应用研究进展概况,” J. 自然灾害 学报, vol. 5, issue 4, pp. 1-5, 1996.

ZHENG Yuanchang, "Progress in basic research and application of disaster prevention and mitigation," J. Journal of Natural Disasters, vol. 5, issue 4, pp. 1-5, 1996.

[2] 陈婧, 刘婧, 王志强, “中国城市综合灾害风险管理现状与对策,” J. 自然灾害学报, vol. 15, issue 6, pp. 17-22, 2006.

CHEN Jing, LIU Jing, WANG Zhiqiang, "Current situation and countermeasures of urban comprehensive disaster risk management in China," J. Journal of Natural Disasters, vol. 15, issue 6, pp. 17-22, 2006

[3] 周彪, 周军学, 周晓猛, 杨勇, “城市防灾减灾综合能力的定量分析, ” J. 防灾科技学院学报, vol. 12, issue 1, pp. 104-112, 2010.

ZHOU. Biao, ZHOU. Junxue, ZHOU. Xiaomeng, YANG. Yong, "Quantitative analysis of the comprehensive capacity of urban disaster prevention and reduction,” J. Journal of Disaster Prevention Science and Technology, vol. 12, issue 1, pp. 104-112, 2010

[4] Jin CHEN, Wen LI, Wenkai CHEN, Suping ZHANG, “Assessment of Earthquake Prevention and Disaster Reduction Capability of CountyLevel Administrative Units in Gansu Province," J. Journal of Risk Analysis and Crisis Response, vol. 7, issue. 4, pp. 214-224, 2017

[5] 王威, 苏经宇, 马东辉, 郭小东, 王志涛, “城市综合防灾与减灾能力 评价的实用概率方法,” J. 土木工程学报, vol. 45, issue. 2, pp. 121124,2012

WANG Wei, SU Jingyu, MA Donghui, GUO Xiaodong, WANG Zhitao, "Practical probabilistic method for evaluation of urban comprehensive disaster prevention and disaster reduction," J. Journal of Civil Engineering, vol. 45, issue. 2, pp. 121-124, 2012

[6] 王威, 田杰, 马东辉, 等, “基于云模型的城市防震减灾能力综合评 估方法, ”. J. 北京工业大学学报, vol. 36, issue 6, pp. 764-770, 2010 WANG Wei, TIAN Jie, MA Donghui, etc, "A comprehensive evaluation method of urban earthquake disaster mitigation capability based on cloud model," J. Journal of Beijing University of Technology, vol.36, issue 6, pp. 764-770, 2010

[7] 张明媛, 刘妍, 袁永博, “基于可变模糊聚类的城镇综合承灾能力评 价研究,”J. 灾害学, vol. 27, issue. 1, pp. 135-138, 2012

ZHANG Mingyuan, LIU Yan, YUAN Yongbo, "Study on the evaluation of urban comprehensive disaster risk capacity based on variable fuzzy clustering," J. Disaster Science, vol. 27, issue. 1, pp. 135-138, 2012

[8] 胡俊锋, 张宝军, 杨佩国, 等, “区域综合减灾能力评价模型和方法 研究与实证分析,”J. 自然灾害学报, vol. 22, issue 5, pp. 13-22, 2013

HU Junfeng, ZHANG Baojun, YANG Peiguo, etc, "Evaluation model and method of regional comprehensive disaster reduction capability and empirical analysis," J. Journal of Natural Disasters, vol. 22, issue 5, pp. $13-22,2013$
[9] Davidson Rachel, Haresh Sban, "An urban earthquake disaster risk index," R. The John A. Blume earthquake engineering Center, report no. 121. Stanford, California: Blume Center, 1997.

[10] Kunihiro A, Takahisa E, Toshio M, "Intercity comparison using evaluation techniques on vulnerability of earthquake disaster--A case study of ordinance, designated city," J. Journal of Japan Society for Natural Disaster Science, vol. 18, issue. 4, pp. 489-500, 2000

[11] Barry N, "Guideline for evaluation and expressing the uncertainty of NIST measurement results, NIST technical note 1297, 1994 edition," S. Gaith-ersburg, National Institute of Standards and Technology, 1994

[12] 刘志亭, 孙福平, “基于 3E 协调度的我国区域协调发展评价,” J. 青 岛科技大学学报, vol. 26, issue. 6, pp. 555-558, 2005

LIU Zhiting, SUN Fuping, "Evaluation of regional coordinated development in China based on 3E coordination," J. Journal of Qingdao University of Science and Technology, vol. 26, issue. 6, pp. 555-558, 2005

[13] 吴跃明, 郎东锋, 张子琦, 张翼, “环境-经济系统协调度模型及其指 标体系, ” J. 中国人口・资源与环境, vol. 2, issue. 6, pp. 47-50, 1996 WU Yuming, LANG Dongfeng, ZHANG Ziqi, ZHANG Yi, "Environment - economic system coordination model and its index system," J. China Population, Resources and Environment, vol. 2, issue 6, pp. 47-50, 1996

[14] 黄友均, 许建, 黎泽伦, “安徽省环境与经济发展协调度的初步分析, ” J. 合肥工业大学学报, vol. 30, issue. 6, pp. 736-738, 2007

HUANG Youjun, XU Jian, LI Zelun, "Preliminary analysis of the coordination degree of environmental and economic development in Anhui province," J. Journal of Hefei University of Technology, vol. 30, issue. 6, pp. 736-738, 2007

[15] 祝爱民, 夏冬, 于丽娟, “基于模糊综合评判的县域科技进步与经济 发展的协调性分析, ” J. 科技进步与对策, vol. 24, issue 11, pp. 193196, 2007

ZHU Aimin, XIA Dong, YU Lijuan, "Analysis on the coordination of technological progress and economic development in county areas based on fuzzy comprehensive evaluation,” J. Technological Progress and Countermeasures, vol. 24, issue. 11, pp. 193-196, 2007

[16] 刘艳清, “区域经济可持续发展系统的协调度研究,” J. 社会科学辑 刊, issue 5, pp. 79-83, 2000

LIU Yanqing, "Study on the coordination degree of regional economic sustainable development system," J. Journal of Social Science, issue 5, pp. 79-83, 2000

[17] 江红莉, 何建敏, “区域经济与生态环境系统动态耦合协调发展研 究-一基于江苏省的数据,” J. 软科学, vol. 24, issue 3, pp. 63-68, 2010

[18] JIANG Hongli, HE Jianmin, "Research on dynamic coupling of regional economy and ecological environment system -- based on data from Jiangsu province,” J. Soft Science, vol. 24, issue. 3, pp. 63-68, 2010

[19] 王滨, 王维早, 齐剑锋, 于开宁, “基于耦合协同理论的泥石流危险 性评价研究,”J. 地球与环境, vol. 33, issue. 2, pp. 276-280, 2012 WANG Bin, WANG Weizao, QI Jianfeng, YU Kaining, "Research on debris flow risk evaluation based on coupling theory," J. Earth and Environment, vol. 33, issue. 2, pp. 276-280, 2012

[20] 王薇, 廖仕超, 徐志胜, “城市综合防灾应急能力可拓评价模型构建 及应用,”J. 安全与环境学报, vol. 9, issue. 6, pp. 167-172, 2009

[21] WANG Wei, LIAO Shichao, XU Zhisheng, "Construction and application of the extension evaluation model for urban comprehensive disaster prevention and response capability," J. Journal of Safety and Environment, vol. 9, issue. 6,pp. 167-172, 2009

作者简介: 宋卓（1994-), 男, 硕士, 主要从事城市基础设施 防灾研究, E-mail: songzhuo@emails.bjut.edu.cn

通信作者: 王威 (1981-), 男, 博士, 副研究员, 主要从事城 市防灾规划、生命线系统抗灾技术研究, E-mail: ieeww@bjut.edu.cn. 